\title{
Gender Differences In Economic Knowledge In Greece
}

Despina Makridou-Bousiou, (E-mail: bousiou@uom.gr), University of Macedonia, Greece

\begin{abstract}
This paper focuses on the effect of gender differences on learning and understanding economics. More particularly, data resulting from an empirical review of relevant bibliography is discussed in the first part and the results of pertinent studies that were carried out in Greek schools are presented in the second part. With respect to high school education, Greek findings demonstrate that when girls receive the same amount of economic instruction as boys in senior high school (lyceum), they score higher than them, despite the fact that performance is measured by TEL, which is a standardized test advantaging the male way of thinking as shown by American researchers. Indeed, the superiority of girls over boys in Greek senior high schools becomes even more important considering the disadvantages of the measurement tool which is further emphasised by the fact that Greek students are not well accustomed to M-C tests. We should note however, that the difference observed is marginally statistically significant. With respect to higher education, the results showed that TUCE III is reliable for Greek economic education and more particularly with regards to the subject of interest in this paper, the boys exhibited considerably and statistically higher economic understanding than the girls. This result is consistent with the bibliography's findings.
\end{abstract}

\section{INTRODUCTION}

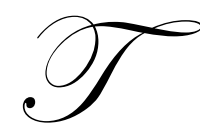

he results of studies pertaining to the role of gender in economic education are not one-sided but lead to a variety of findings. In 1979 Siegfried provided us with a literature review of this type of study which deals with gender differences in understanding economics - stock of knowledge at a point in time, and increase in understanding of economics - flow of knowledge over time. Siegfried ascertains that the majority of researches examining the level of economic understanding or learning, using economically standardized tests as measurement tools, find important differences with regards to gender, where men outperform women. Specifically, he observes that in $2 / 3$ of the studies examining the level of economic understanding taking gender into account, men exhibit statistically higher levels of understanding than women. While only $1 / 3$ of the studies examining the learning of economics proves that men perform better than women.

Siegfried concludes that men demonstrate higher performance levels than women upon entry into university. However, these gender differences appear only at the beginning of their university studies, and are eliminated during the course of their studies, as students understand and learn at the same pace regardless of gender.

In addition, other studies (Ferber, Birnhaum and Green, 1983; Lumsden and Scott, 1987; Soper and Walstad, 1988; Heath, 1989; Watts and Lynch, 1989; Gohmann and Spector, 1989; Tay, 1994; Dynan and Rouse, 1997) also confirm that men tend to understand economics better than women.

\section{High School Education}

Soper and Walstad (1987) report that of those who participated in the national norming of the TEL, males had a mean score of 22.60 questions correct out of 46 TEL questions and females had a mean score of 21.51 questions correct. Although the gender difference was small, it was statistically significant. 
In a study aiming at "analyzing gender differences in economic knowledge, correcting for sample selfselectivity bias" (pp: 227), Heath (1989) used data from the national evaluation of TEL. The researcher notes "in order to assess the effects of self-selectivity, the sample was composed of those students whose states or districts did not require a course in economics to graduate". The results showed that men were more likely to select economics courses than women. Furthermore, the higher a student's general mean score or if the student had previously selected a course in Business Management and Administration or algebra, the more likely the student was to choose an economics course. Moreover, Heath states that gender differences in economic understanding appear as early as in adolescence and thus "the high school years are crucial in the establishment of these observed gender differences, differences that persist well into college" (1989:226) and that formal economic education can eliminate these differences.

Contrary to the studies showing that statistically, male students in senior high school perform better than female students, over time a number of studies have demonstrated a lack of significant differences between the male and female gender with respect to understanding and learning economics.

More specifically, according to Davison and Kilgore (1971), there are no gender related differences in the understanding of economics throughout senior high school education. The differences begin to appear when students graduate from senior high school.

MacDowell et al., 1977, conducted a large scale survey, collecting data from 2000 students aged 14-15 years old, and found that gender does not count as a decisive factor in learning economics in senior high school. They report that based on previous data, significant gender related differences in learning begin to arise somewhere between the last years of senior high school and the second year of university.

In a study conducted on a team of senior high school students of diverse origin, school of studies, and place of residence, using the Test of Economic Literacy, Hann (1982) found that girls who had received the same amount of economic instruction in high school as boys, performed equally to them, whether performance was measured by grades or standardized tests.

Buckles and Freeman (1983) report that, further to a study conducted on high school students, they found that gender is not statistically important in economic learning and understanding. Of course, they note that it would be a good idea for the study to be conducted once again, on a larger "school system".

Finally, Watts (1987) suggested that, although pre-course economic knowledge tends to favor boys, formal economic instruction can reduce differences which are observed when the course begins and that there are other variables in some school districts which eliminate gender differences in performance even before formal instruction.

He demonstrated that men achieve higher levels of understanding of economics from the very first stages of their education, but in subsequent stages, men and women tend to accumulate knowledge at the same pace, and this eventually eliminates the gap between them.

\section{Higher Education}

In a study conducted at "Purdue University" in the period 1984-1985, on a sample of 2,800 students, Watts and Lynch (1989) report that the results provide evidence to support the significance of gender on students' performance in economics. "Our results on gender are broadly in line with previous work, but we add one case to the group of findings where gender is both positively significantly related to student learning. Surprisingly, the link also carries over to grade equations, except in the Microeconomics course. The gender differences in the Microeconomics course are least expected because it is often argued that males perform better than females on multiple-choice questions, and that this course uses fewer multiple-choice questions than other courses".

Gohmann and Spector (1989) examined the contention that content ordering may be more effective in classes that require analytical skills, such as economics. The study was carried out on a Macroeconomics course using a sample of 191 students of which $42 \%$ were girls. The examination was carried out providing students with subjects in 
two different forms. The first form included 78 questions that were arranged in the order in which the material was taught in class, while the second form included the same questions in a different order. The girls exhibited inferior performance in the test as compared to the boys (difference of 5\%); in fact, this difference was not only found to be statistically significant, but also significantly related to the gender factor, as the coefficient on gender was the only significant coefficient.

In a study conducted by Tay (1994), using data from the Singapore "School of Accountancy and Business" during the academic year 1991-1992, and a sample of 1,314 first year students, it was found that males demonstrated higher performance levels than females. In addition, Tay notes that the assumption that the questions of development used in the examinations would favor female students was not confirmed, perhaps because the type of lectures - big audiences - as well as the cultural biases and stereotypes had greater effects on students' performance.

Dynan and Rouse (1997), in a study conducted at Harvard University with a view to identify some of the factors that explain the racial differentiation in undergraduate students' decisions to major in economics, found that "women do less well in economics relative to their other courses than men (Dynan and Rouse, 1997: 365)".

Finally, Williams, Wardauer and Duggal (1999) conducted a study on students of economics, with an average level of studies in statistics and economics courses. Further to this study, they dispute the publicly accepted opinion that men regularly exhibit higher performance levels than women in questions that require quantitative analysis, while women perform better in questions that require verbal/theoretical skills. The performance differences between the two genders do not increase as students follow more difficult courses after the first year of university studies. Also, the examination results in the economics courses do not show remarkable gender related differences.

\section{Assumptions That Explain The Differentiation}

There exist many controversial reasons for these differences; sex biased socialization might encourage boys towards, and discourage girls from the study of quantitative and business oriented courses; another explanation emphasizes the different maturation rates for boys and girls, or physiological differences such as right-left brain dominance affecting student performance in economics; girls mature earlier than boys and are comparatively superior in verbal skills, whereas boys mature later and possess more spatial skills which are considered associated with economic principles. Finally, evidence suggests that teachers' attitudes and learning material can be sex biased as well (MacDowell, Senn and Soper, 1977; Ladd, 1977; Jackstat and Grootaert, 1980, Williams, Waldauer and Duggal, 1992; Anderson, Benjamin and Fuss, 1994; Ferber, 1990).

More specifically, MacDowell, Senn and Soper (1977:30) group the above socio-cultural explanations into four categories: (a) the question of identity that requires the woman to seek a spouse based on the stereotype of young age, one of which is that the business world belongs to the male world; (b) the gender stereotypes in low income families, where boys have priority over going to college; (c) the greater dependence of girls in relation to the boys. Perhaps economics are taught in ways that suit boys better than girls; (d) differences in maturation rates. Given that women generally mature earlier than men, it is likely that they have a comparative advantage in linguistic skills, while men have a comparative advantage in numerical and spatial skills. Furthermore, Ferber (1990), Horvath, et al (1992), and Robb (1999) add the fifth probability, that the behavior, the professor's gender and the teaching material are accountable for the difference. Of course, it is likely that two or more of the above reasons coexist simultaneously.

Moreover, there was and still is a lot of discussion regarding the potential biases regarding the examination methods (women don't do well with multiple-choice tests, a common examination method in introductory economics), or as Walstad and Robson report (1997:155) "the fixed or constructed-response format of an economics test may influence test results". More analytically, researchers were worried about the type of instrument used to measure performance; the standardized form of examination of economic knowledge, which is multiple-choice tests, was found to benefit male performance in economics and disadvantage females who did better in essay questions. Ferber et al (1983) found that boys' superiority was confined to multiple-choice tests while girls did significantly better in essay questions, and they suggested that the methods of assessment and evaluation of economic knowledge should be revised. Lumsden and Scott (1987) explored this issue even further and found that boys are better at using 
knowledge to analyze problems, a skill that is required by M-C tests, whereas girls are better at writing, memorizing, synthesizing and evaluating skills required by essay questions. Thus, measurement by M-C tests only is not reliable. This finding is further supported by Siegfried and Walstad (1990), who also found that male students perform better on multiple-choice examinations, whereas female students perform substantially better on essay examinations.

\section{THE SITUATION IN GREECE}

At the University of Macedonia in Greece, many research efforts have been made in this direction. The first study in which an attempt is made to examine whether there are gender differences in economic understanding - stock of knowledge - was conducted at the University of Macedonia in 1990 (Makridou-Bousiou, 1991). Data was collected from a population of 20,541 high school students, which included all the third graders enrolled in all three types of public senior high schools (lyceum) in Northern Greece (257 schools in all). The third grade was chosen because students at this level are taught an integral course of "basic economic principles"1. A sample of 2,509 students was selected following a multiphase procedure. First, the total number of students was split into three categories according to the type of school and then distributed to the 13 administrative regions of Macedonia in proportion to the population size. Finally, classes of a typical size of about 25 students were chosen at random in each region.

Due to the unavailability of a Greek measurement tool for economic knowledge, the American Test of Economic Literacy (TEL) (Soper, 1979) was translated into Greek after checking its reliability (Makridou-Bousiou and Papanastassiou, 1994:28-31). The TEL is a nationally normed and standardized test for basic economic understanding of students in eleventh and twelfth grade, consisting of two forms of 46 multiple-choice questions. The TEL is a valid and reliable test according to the bibliography (Soper and Walstad, 1988:38). It is used in most projects of a similar nature at the senior high school educational level.

Scores for females and males are presented in Table 1. In contrast to American findings where mean scores for males were higher than those for females, we see that mean scores for Greek male students are lower (18.04 \pm 5.50) than those for female students $(18,82 \pm 5.13)$. Furthermore, Greek findings demonstrate that when girls receive the same amount of economic instruction as boys in senior high school (lyceum), they score higher than them, despite the fact that performance is measured by TEL which is a standardized test benefiting the male way of thinking as shown by American researchers. Indeed, the superiority of girls over boys in Greek senior high school becomes even more important considering the disadvantages of the measurement tool, which is further emphasized by the fact that Greek students are not well accustomed to M-C tests. We should note however, that the difference observed is marginally statistically significant. An important observation at this point is that the difference between the boys and the girls in the Greek lyceum can be due to the particularities of the Greek educational system, which places more emphasis on memorization rather than analytical and critical thinking.

Table 1

\begin{tabular}{|c|c|c|c|}
\hline Gender & Mean & Standard Deviation & Number \\
\hline Females & 18.82 & 5.13 & 1368 \\
\hline Males & 18.04 & 5.50 & 1105 \\
\hline
\end{tabular}

Over time, other efforts were made in assessing the difference in the Greek educational system. Studies were conducted within the framework of university projects under the supervision of the writer - initially in senior high school education and subsequently in higher education.

Three studies were designed within the framework of senior high school education for students in the third grade of lyceum, just as in the original 1990 study and for the same reasons. TEL was used as a measurement tool,

\footnotetext{
${ }^{1}$ More on the Greek educational system can be found in: (a) Bousiou, D. And Mr, Panourghia (1993). Economics Education in Greek Secondary Schools Economia, 6 (Winter):62-63, and (b) Makridou-Bousiou, D. and S., Tsopoglou, (2002) "Economic Education in Greece at High School Level" (2002) (website: http://www.sowi-onlinejournal.de/2002-2/greece_bousiou_ua.htm)
} 
(Soper and Walstad, 1987, 2ed; Walstad and Rebeck, 2001, 3ed). All the studies measured the level of economic understanding.

The first study was conducted in 1996 (Giannoussi and Sakkagianni, 1996) on students within the central Macedonia region and in three different prefectures. There were 1,159 students in this region; consequently and as per the theory, the sample was adjusted to 250 students, at a confidence level of 0.05 . The girls performed considerably better than the boys, with a mean score of 17.68 questions correct out of 46 TEL questions, as compared to a mean score of 15.86 questions correct for the boys. This difference was statistically significant, and the results are partly in line with the results of the 1990 study.

The second study was conducted in 2003 (Kesisoglou and Zafeiri, 2003) on students from four different cities and two different regions - Thessaloniki, Kavala in Macedonia and Sperxeiada, Makrakomi in Sterea Greece. The sample was comprised of 164 students. The results showed students' performance on TEL ( $3^{\text {rd }}$ ed.) is not influenced by gender, since the difference was calculated at $0,05 \%$ in favor of the men. More analytically, females had a mean score of $18.93 \pm 4.59$ questions correct out of 40 TEL questions and males had a mean score of $18.95 \pm 6.18$ questions correct, a difference that is not statistically significant, making the results consistent with previous studies (Hann, 1982 Buckles and Freeman, 1983).

The third study was conducted in 2004 (Panagiotopoulou, 2004) on students from the two largest cities of Greece - Thessaloniki and Athens - and seven different schools. The sample was comprised of 157 students. Analysis of the data showed that students' performance is not influenced by gender, as the difference between the girls and the boys was $0,2 \%$. (Females had a mean score of 25.52 questions correct and males had a mean score of 25.45 questions correct, which was not statistically significant). This result converges with the result of the 2003 study as well as the results of Hann (1982).

\section{STUDIES CONDUCTED WITHIN THE FRAMEWORK OF HIGHER EDUCATION}

In 1995 a pilot study was conducted on first year students at the University of Macedonia, using the Test of Understanding in College Economics, TUCE III (Saunders, 1991) as a measurement tool. The fundamental objective of the study was to assess the reliability of TUCE III in the Greek educational system. This would allow the completion of further research using bigger samples, in order for the results to have external validity. TUCE III was selected because in Greece there does not exist a valid and reliable calculating economic test for this level of education. The sample constituted 94 students from the economics department that had been taught introductory Microeconomics and Macroeconomics. The results showed that TUCE III is reliable for Greek economic education and more particularly, with regards to the subject of interest in this report, the boys performed considerably and statistically better than the girls in economic understanding. This result is consistent with the bibliography's findings (Dynan and Rouse, 1997; Tay, 1994; Gohmann and Spector, 1989; Ferber, Birnbaum and Green, 1983; Lumsden and Scott, 1987).

Today, two studies are in progress at the University of Macedonia that use TUCE III and that are expected to be completed in the spring of 2006. We are hopeful that, after the processing of the data, we will be in a position to contribute to the relevant bibliography with useful information.

\section{CONCLUSIONS}

The results of studies based on the Greek situation at the senior high school level do not identify with the findings of the majority of empirical data from other studies, which, over time, examined the effect of gender on the understanding of economics. In contrast, the findings of pilot studies in higher education concur with the findings of relative studies. We believe that the expected results of studies that are currently being performed at the University of Macedonia will lead us to the same conclusions. We would certainly like to stress that the results of Greek circumstances, especially at the senior high school level, must be interpreted within the framework of the Greek educational system that, to this day, and despite all efforts, is characteristic of being predominated by memorization rather than critical thinking. 


\section{REFERENCES}

1. Anderson, G., D. Benjamin, and M. Fuss (1994). The determinants of success in university introductory economics courses. The Journal of Economic Education, 25 (Spring): 99-119.

2. Davison, D. G. and J. H. Kilgore (1971). A Model for Evaluating the Effectiveness of Economic Education in Primary Grades, The Journal of Economic Education, 3 (Fall) 17 - 25.

3. Dynan, K. and C. E. Rouse (1977). The Underrepresentation of Women in Economics: A Study of Undergraduate Economics Students, The Journal of Economic Education, 28 (Fall): 350 - 368.

4. Ferber, M. A. (1990). Gender and study of economics. In The principles of economics course, ed. Phillip Saunders and William B. Walstad, 44-60. New York: McGraw-Hill.

5. Ferber, M. A., B. G. Birnbaum, and C. A. Green (1983). Gender Differences in Economic Knowledge: A Reevaluation of the Evidence. The Journal of Economic Education, 14 (Spring): 24 - 37.

6. Giannousi, M. and Ф. Sakkagiani (1996). An application of TEL in Regular, Technical and Professional Lyceum of Central Macedonia, University Project, University of Macedonia, Thessaloniki, Greece

7. Gohmann, S. F. and L. C. Spector (1989). Test Scrambling and Student Performance. Journal of Economic Education, 20 (Summer): 235-238.

8. Hann, C. L. (1982). Are there Gender Differences in High School Economics in the Eighties? Journal of Economic Education, 13 (Summer): 57-65.

9. Heath, J. A. (1989). An Econometric Model of the Role of Gender in Economic Education, The American Economic Review, 79 (May): 226 - 235.

10. Horvath, J., B. Q. Beudin, and S. P. Wright (1992). Persisting in introductory economics course: An exploration of gender differences. The Journal of Economic Education, 23 (Spring): 101 - 108.

11. Jackstadt, S. I. and C. Grootaert (1980). Gender, gender stereotyping, and socioeconomic background as determinants of economic knowledge and learning. Journal of Economic Education, 12 (Winter): 34 - 40.

12. Kesisoglou, S. and G. Zafeiri (2003). Student gender role in the understanding of economics: A Greek lyceum approach, university project, University of Macedonia. Thessaloniki, Greece

13. Ladd, H. F. (1977). Male-female differences in pre-college economic education. In Perspectives on economic education, ed. D. R. Wentworth, W. L. Hansen, and Sharryl H. Hawke, 145-155. New York: Joint Council on Economic Education (now National Council on Economic Education).

14. Lumsden, K. G. and A. Scott (1987). The Economics Student Re-examined: Male - Female Differences in Comprehension. Journal of Economic Education, 18 (Fall:) 365 - 375.

15. MacDowell, M. A., Senn, P. R., and Soper, J. C. (1977). Does Sex Really Matter? Journal of Economic Education, 9 (Fall): 28 - 33.

16. Makridou-Bousiou, D. and D. Papanastassiou (1994). The test of Economic Literacy and the economic understanding of Greek Grammar School, Economia, 7 (Summer):28-31

17. Makridou-Bousiou, D. (1991). Economic Literacy in Secondary Education. Doctoral thesis, University of Macedonia, Salonica

18. Panagiotopoulou, A. (2004). Gender differentiation in the understanding of economics. Results from an application in Greek Lyceum, University project. University of Macedonia. Thessaloniki, Greece

19. Robb, E. R. and Robb, A. L., (1999). Gender and the Study of Economics: The Role of Gender of the Instructor, Journal of Economic Education, 30 (Winter): 3 - 19.

20. Saunders, P. (1991). Test of Understanding in College Economics. Third Ed. New York: Joint Council on Economic Education (now National Council on Economic Education).

21. Siegfried, J. and W. Walstad (1990). Research on teaching college economics. In The principles of economics course, ed. Phillip Saunders and William B. Walstad. New York: McGraw-Hill.

22. Siegfried, J. J. (1979). Male - Female Differences in Economic Education: a Survey, The Journal of Economic Education, 10 (Spring): 1 - 11.

23. Soper, J. C. and W. B. Walstad (1988). What Is School Economics? Posttest Knowledge, Attitudes, and Course Content, Journal of Economic Education, 19 (Winter): 37-51.

24. Soper, J. C. and W. B. Walstad (1987). Test of economic literacy: Examiner's manual, 2d ed. New York: Joint Council on Economic Education

25. Tay, R. S. (1994). Students' Performance in Economics: Does the Norm Hold Across Cultural and Institutional Settings? Journal of Economic Education, 25 (Fall): 292-301 
26. Walstad, W. B. and K. Rebeck (2001). Test of Economic Literacy: examiner's Manual, Third Ed. New York. National Council on Economic Education).

27. Walstad, W. B and J. C. Soper (1989). What is high school economics? Factors contributing to student achievement and attitudes. Journal of Economic Education, 20 (Winter): 23 - 38.

28. Walstad, W. B and D. Robson (1997). Differential Item Functioning and Male-Female Differences on Multiple-Choice Test in Economics. Journal of Economic Education, 28 (Spring): 155 - 172.

29. Watts, M. (1987). Student Gender and School District Differences Affecting the Stock and Flow of Economic Knowledge, The Review of Economics and Statistics, 49 (August): 561 - 66.

30. Watts, M. and G. Lynch (1989). The principles courses revisited. The American Economic Review 79 (May): $236-41$

31. Williams, L. M., C. Wardauer, and V. G. Duggal (1987). Gender Differences in Economic Knowledge: An Extension of the Analysis, Journal of Economic Education, 23 (Summer): 219 - 31.

\section{NOTES}




\section{NOTES}

